\title{
O PROGRAMA CRIANÇA FELIZ E SUAS CONTRIBUIÇÕES PARA O DESENVOLVIMENTO DA CRIANÇA NA PRIMEIRA INFÂNCIA: APONTAMENTOS SOBRE O CASO DE RIBEIRÃO PRETO/SP
}

THE "PROGRAMA CRIANÇA FELIZ" AND ITS CONTRIBUTIONS FOR THE DEVELOPMENT OF CHILDREN IN FIRST CHILDHOOD: REFERENCES ON THE CASE OF RIBEIRÃO PRETO/SP

Ronan da Silva Parreira Gaia', Thais Peterossi Candido², Washington de Bessa Barbosa Júnior ${ }^{3}$

RECEBIDO: 15/04/2019 | ACEITO: 26/05/2019

DOI: $10.5902 / 2317175837746$

\section{RESUMO}

O trabalho aqui apresentado tem como objetivo realizar reflexões acerca do Programa Criança Feliz (PCF) e suas contribuições para o desenvolvimento da criança na primeira infância. A referência para o estudo foi a análise das experiências vivenciadas através da atuação profissional dos autores no referido programa em Ribeirão Preto (SP) e como metodologia a análise bibliográfica acerca dos assuntos abordados. A partir das reflexões construídas neste texto, é possível apresentar o trabalho do programa em pauta, sua metodologia e fundamentação teórica, intersetorialidade e sua pertinência para o desenvolvimento da criança na primeira infância.

Palavras-chave: Assistência Social; Primeira Infância; Desenvolvimento Infantil.

\footnotetext{
1 Especialista em Direitos Humanos, Educação Especial e Inclusiva, Educação e Sociedade, Gestão Pública e Psicopedagogia Institucional pela Faculdade de Educação São Luís - FESL. Licenciado em Pedagogia pela Faculdade Filadélfia - FAFIL. Supervisor Técnico do Programa Criança Feliz em Ribeirão Preto - SP.

2 Especialista em Psicopedagogia Institucional pela Faculdade de Educação São Luís - FESL e em Teorias e Técnicas Psicanalíticas pela Faculdade de Tecnologia, Ciências e Educacão - FATECE. Psicóloga pela Universidade Estadual "Júlio de Mesquita Filho" - UNESP. Supervisora Técnica do Programa Criança Feliz em Ribeirão Preto - SP. 3 Mestre em Direito Público pela Universidade de Ribeirão Preto - UNAERP. Bacharel em Direito e pela Universidade de Ribeirão Preto - UNAERP. Licenciado em Pedagogia pelo Centro Universitário Claretiano - CEUCLAR. Bacharel em Serviço Social pelo Centro Universitário Newton Paiva/Centro Universitário UNISEB/COC.
} 


\section{ABSTRACT}

The objective of this study is to present some reflections about the "Programa Criança Feliz - PCF" and its contributions to the development of children in early childhood, having as reference the analysis of the experiences lived through the professional performance of the authors in the program in Ribeirão Preto - SP. Based on the reflections constructed in this text, it is possible to present the work of the program in question, its methodology and theoretical basis, intersectoriality and its pertinence for the development of the child in early childhood.

Keywords: Social Assistance; Early Childhood; Child Development.

\section{Introdução}

A Assistência Social, direto do cidadão que dela necessita e dever do Estado, Política de Seguridade Social não contributiva, de natureza interdisciplinar, é realizada por meio de um conjunto de ações, de iniciativa pública e social, as quais proveem os mínimos sociais e atende às necessidades básicas. A Assistência Social objetiva proteção social, vigilância socioassistencial, defesa e garantia de direitos, como a vida, a redução de danos, a prevenção da incidência de riscos, o enfrentamento da pobreza, o atendimento das contingências sociais e a promoção da universalização dos direitos sociais. Integrada às demais políticas públicas sociais setoriais e transversais, não se confunde com Assistencialismo, tampouco com Serviço Social e muito menos com Assistente Social, nos termos previstos na Constituição Federal de 1988 e na Lei Orgânica da Assistência Social (BRASIL, 1988; BRASIL, 1993a).

Assistente Social é o profissional inscrito e habilitado no correspondente Conselho Regional de Serviço Social (CRESS), com formação em Serviço Social, curso universitário em nível de graduação e profissão regulamentada, constituindo serviço técnico desenvolvido em organização pública ou privada, tudo nos termos da Lei Federal n. 8.662, de 1993 (BRASIL, 1993b). Assistencialismo, por sua vez, é ação e oferta de serviços, movida pela compaixão humana, visando atendimento de questões imediatistas, praticadas por meio de doação, favor, boa vontade e interesse de alguém e não um direito de cidadania garantido em lei (ALAYON, 1995; GAIA, 2016).

A Assistência Social é um dos campos de trabalho do Assistente Social e do Serviço Social, um dos trabalhadores/as do Sistema Único de Assistência Social (SUAS), mas não só deste profissional. Este é campo aberto para atuação de outros profissionais de formação universitária (GAIA, 2016), como o Psicólogo, o Pedagogo, o Sociólogo, o Antropólogo, o Advogado, o Economista, o Contador, o Terapeuta Ocupacional, o Administrador, o Economista Doméstico e o Musicoterapeuta, enquanto técnicos, na gestão ou operação das ações daquela Política Pública, nos termos da Resolução do Conselho Nacional de Assistência Social - CNAS n. 017/ 2011, além dos profissionais de formação em nível médio ou fundamental, de que trata a Resolução CNAS n. 09/2014 (BRASIL, 2011; BRASIL, 2014). Face ao exposto, é pertinente destacar que a Assistên- 
O PROGRAMA CRIANÇA FELIZ E SUAS CONTRIBUIÇÕES PARA O DESENVOLVIMENTO DA CRIANÇA NA PRIMEIRA INFÂNCIA: APONTAMENTOS SOBRE O CASO DE RIBEIRÃO PRETO/SP

cia Social encontra suporte na Lei Orgânica da Assistência Social (LOAS) (Lei $n$. 8.743/93) e tem o território, a matricialidade familiar e a descentralização administrativa com base operacional municipalizada (que não se confunde com prefeiturização, mas sim com Estado por dever, gestor e primazia de oferta mas com coparticipação, suplementação e complementação da sociedade civil organizada e da família) como base de organização de suas ações. As atividades são ofertadas em forma de: Serviços, Programas, Projetos e Benefícios Socioassistenciais levando em conta tanto a organização do território (BRASIL, 1993), como a situação de vulnerabilidade ou risco pessoal, social, afetivo ou econômico do usuário público-alvo que necessitam, por direito, não por favor, do atendimento.

O Programa Governamental Primeira Infância no SUAS, no qual tecnicamente se insere o Programa Criança Feliz (PCF), objeto de estudo do presente trabalho, constitui-se como programa de Assistência Social nos termos do artigo 24 da LOAS, como ações socioassistenciais complementares e integradas a serviços e benefícios socioassistenciais, (no caso integrado e complementando o PAIF/CRAS - Serviço de Atendimento a Indivíduos e Famílias/CRAS/SUAS), que visam qualificar, melhorar e incentivar os benefícios e serviços de Assistência Social. O Programa Governamental Primeira Infância no SUAS é ação de Proteção Social Básica (PSB), concebida pelo então Ministério do Desenvolvimento Social (MDS), hoje Ministério da Cidadania, dentro da Políticas Pública Social Setorial de Assistência Social no âmbito do SUAS e voltada e atendendo a Política Pública Social Transversal e ao Plano Nacional pela Primeira Infância (política pública intersetorial e interdisciplinar), o qual é operado de forma municipalizada, diretamente pela Prefeitura ou desta em parceria com Organizações da Sociedade Civil (OSCs), reconhecidas como Entidades de Assistência Social, a partir de parceria no regime de mútua cooperação para a consecução de finalidades de interesse público e recíproco nos termos da Lei Federal n. 13.019, de 2014 e alterações posteriores. (BRASIL, 1993; BRASIL, 2014) Sobre serviços socioassistenciais, podemos concebê-los como aquelas ações de Assistência Social que ocorrem junto a população residente em um determinado território (SIGAS, s.d.) que delas necessitam. Cabe informar que PCF tem como embasamento metodológico o "Programa Primeira Infância Melhor" (PIM/RS), implantado oficialmente pela Portaria n. 15/2003, instituído como Política Pública pela Lei. Estadual n. 12.544/06 (RIO GRANDE DO SUL, 2006) e baseado no Programa "Educa a tu hijo" de Cuba e o manual de "Cuidados para o Desenvolvimento da Criança (CDC) - UNICEF/OPAS" (BRASIL, 2017).

Baseado nessas informações, algumas indagações são necessárias: a) qual o parâmetro adotado para definir o público do programa? b) ao estabelecer como público prioritário apenas gestantes e crianças beneficiárias do Programa Bolsa Família (PBF) e do Benefício de Prestação Continuada (BPC), não estaria subentendido que apenas essas famílias tem dificuldades em desenvolver-se, estabelecer vínculos e definir seus papeis?; e c) a frequência das 
visitas domiciliares, especificamente as visitas semanais, não poderia interferir na rotina escolar daquelas crianças que frequentam a Educação Infantil em período integral e/ou na rotina haja vista que, obviamente, as visitas domiciliares do programa só podem ocorrer em domicílio?

Dessa forma, iniciaremos nossa reflexão acerca da constituição do Programa Criança Feliz e seus aspectos jurídicos e sociais, assim como seu alcance e contribuição ao desenvolvimento e proteção social de crianças em primeira infância e a operação dos serviços socioassistenciais do CRAS, em especial o PAIF, no atendimento a parcela vulnerável de famílias com indivíduos nesta condição, nem como sua estrutura e organização no município de Ribeirão Preto. Posteriormente, apresentaremos algumas considerações acerca do desenvolvimento humano da criança e a importância do vínculo afetivo neste processo.

\section{A organização do Programa Criança Feliz - PCF no município de Ribeirão Preto}

Instituído por meio do Decreto Federal n. 8.869, de 05 de outubro de 2016, como resposta ao Marco Legal da Primeira Infância (Decreto n. 13.257, de 08 de março de 2016). (BRASIL, 2016a; BRASIL, 2016b), o Programa Primeira Infância no SUAS, Programa Criança Feliz (PCF), tem como objetivos:

- Promover o desenvolvimento humano a partir do apoio e do acompanhamento do desenvolvimento infantil integral na primeira infância;

- Apoiar a gestante e a família na preparação para o nascimento e nos cuidados perinatais;

- Colaborar no exercício da parentalidade, fortalecendo os vínculos e o papel das famílias para o desempenho da função de cuidado, proteção e educação de crianças na faixa etária de até seis anos de idade;

- Mediar o acesso da gestante, das crianças na primeira infância e das suas famílias às políticas e serviços públicos de que necessitem;

- Integrar, ampliar e fortalecer ações de políticas públicas voltadas para as gestantes, crianças na primeira infância e suas famílias. (BRASIL, 2017, p. 9)

No Município de Ribeirão Preto, situado no nordeste paulista, o Programa Criança Feliz integra o Sistema Único de Assistência Social (SUAS) e é operado desde 20 de novembro de 2017, pelo Instituto Protagonismo (Instituto de Desenvolvimento Social e da Cidadania), sob supervisão do Departamento de Proteção Social Básica (DPSB) da Secretaria Municipal de Assistência Social (SEMAS), integrado e complementando o PAIF dos - Centros de Referência de Assistência Social (CRASs) 2, 3, 5 e 6. É pertinente destacar o caráter intersetorial do PCF, haja vista sua relação com diversas políticas públicas (de Assistência 
O PROGRAMA CRIANÇA FELIZ E SUAS CONTRIBUIÇÕES PARA O DESENVOLVIMENTO DA CRIANÇA NA PRIMEIRA INFÂNCIA: APONTAMENTOS SOBRE O CASO DE RIBEIRÃO PRETO/SP

Social, Educação, Cultura, Saúde, Direitos Humanos, entre outras) tendo como objetivo final o desenvolvimento da criança em primeira infância. Tem sua coordenação nacional na Secretaria Nacional de Promoção do Desenvolvimento Humano, do Ministério do Desenvolvimento Social (MDS) (BRASIL, 2017), a qual se expressa no programa por meio do acompanhamento e coparticipação do Comitê Municipal Intersetorial do Programa Criança Feliz, onde se fazem representar as políticas de educação, saúde, assistência social, cultura e representantes comunitários da Sociedade Civil.

Segundo o Guia para Visita Domiciliar (BRASIL, 2017, p. 14), o programa tem como público prioritário "gestantes, crianças de até 3 (três) anos e suas famílias beneficiárias do Bolsa Família; (...) crianças de até 6 (seis) anos e suas famílias beneficiárias do BPC (crianças com deficiência, portanto); (...) crianças de até (seis) anos afastadas do convívio familiar em razão de aplicação de medida protetiva". É oportuno mencionar que com a promulgação da Resolução n. 6, de 19 de fevereiro de 2019, amplia-se o público prioritário do Programa Criança Feliz também para crianças na primeira infância e gestantes inseridas no Cadastro Único (BRASIL, 2019).

No que se refere às funções do Visitador Social, resumidamente, é o "profissional responsável por planejar e realizar a visita domiciliar as famílias do Programa (...) com apoio e acompanhamento do supervisor" (BRASIL, 2017, p. 17). Este profissional é responsável por identificar a demanda do indivíduo e da família, apresentar e refletir junto ao/aos Supervisor (es) Técnico(s) do Programa sobre a demanda, ocorrência e intercorrência observada, para que seja possível reportar os aspectos relevantes observados ao PAIF/CRAS, qualificando a ação de atendimento naquele equipamento socioassistencial administrativamente descentralizado, na perspectiva da territorialização e matricialidade familiar.

A equipe do Programa Criança Feliz no município de Ribeirão Preto é composta por 2 (dois) Supervisores Técnicos e 16 (dezesseis) Visitadoras Sociais, entre Prestadoras de Serviços e Estagiários em Estágio Acadêmico Remunerado. Estes últimos encontram-se sob supervisão técnica profissional devida, intermediada, em coparceira, pelo Instituto de Apoio a Programas de Estágio e Aprendiz - IAPE/Ribeirão Preto.

A estratégia metodológica essencial da ação do PCF é a visitação em domicílio por Visitadores Sociais e a meta municipal é o atendimento periódico de até 500 (quinhentos) indivíduos-beneficiários por mês, entre gestantes e crianças em primeira infância na perspectiva das diretrizes do PCF. Diante disso, é pertinente salientar que o município de Ribeirão Preto conta com 7 (sete) Centros de Referência de Assistência Social (CRAS), no entanto, estão envolvidos no Programa Criança Feliz apenas 4 (quatro). Baseando-se na análise municipal das regiões com maior índice de vulnerabilidade social, as metas de indivíduos a serem visitados foram estruturadas do seguinte modo (PMRP, s.d): 
- CRAS 2 (Região Norte): 100 indivíduos e suas respectivas famílias;

- CRAS 3 (Região Noroeste): 100 indivíduos e suas respectivas famílias;

- CRAS 5 (Região Sudoeste): 200 indivíduos e suas respectivas famílias;

- CRAS 6 (Região Norte): 100 indivíduos e suas respectivas famílias.

Faz-se necessário mencionar que a equipe do programa no município também realiza visitas domiciliares às famílias de zona rural. No território estabelecido, há destaque para os assentamentos da Fazenda da Barra (PDS da Barra), região do Complexo Urbano Ribeirão Verde, território de atendimento do CRAS 6 (inaugurado em 25 de janeiro de 2018 e criado a partir do então existente Núcleo de Apoio ao CRAS 2).

No que se refere a periodicidade das visitas domiciliares, é válido destacar que, inicialmente, a equipe realiza as visitas domiciliares de acordo com o exposto pela Portaria n. 2.496/2018 (MDS) As gestantes e suas famílias recebem visitas domiciliares com periodicidade mensal, duas visitas domiciliares mensais às crianças de trinta e sete a setenta e dois meses e seus respectivos familiares e quatro visitas domiciliares mensais às crianças de zero a trinta e seis meses e seus respectivos familiares (BRASIL, 2018). É válido ressaltar que o Guia para Visita Domiciliar (BRASIL, 2017), assim como a Portaria n. 2.496/2018 (MDS) em seu artigo n. 3 (BRASIL, 2018), concebem que cada visitador social deve realizar visitas domiciliares e acompanhar até 30 (trinta) indivíduos e suas respectivas famílias. No que se refere a inclusão dos indivíduos atendidos pelo PCF, segundo orientações informadas durante a semana de capacitação da equipe de Visitadoras Sociais, realizada pela SEMAS em parceria com a Diretoria Regional de Assistência e Desenvolvimento Social (DRADS), é necessário que a gestante e/ou responsável pela criança realiza a assinatura do Termo de Adesão ao Programa, ou ainda a assinatura do Termo de Desistência, informando o motivo do desinteresse pela participação no Programa Criança Feliz.

Portanto, ao receber (dos respectivos CRAS envolvidos) as listagens de indivíduos elegíveis para participação no PCF em pauta e a equipe de Visitadoras realizar o primeiro contato por meio de visita domiciliar inicial, os possíveis participantes são convidados para as Reuniões de Apresentação do Programa Criança Feliz (realizadas nos CRAS ou em Núcleos de acordo com a orientação das Coordenadoras de CRAS ou Técnicas de Referência no Programa por CRAS). Os profissionais envolvidos dedicam a estes até três visitas preliminares, mantendo-os se ocorrer a adesão ou desligando-os se não ocorrer o interesse voluntário na adesão.

Semanalmente são realizadas reuniões de equipe e, mediante prévia programação, atividades de educação continuada permanente, com capacitação temática advinda das demandas e necessidades apuradas ou postas durante os encontros com os responsáveis. O objetivo destas atividades é fortalecer a equipe do programa, refletir sobre seus objetivos e as dificuldades encontradas durante as visitas domiciliares. Do mesmo modo ocorre a reunião de supervisão individual, na qual o visitador social apresenta e discute as demandas observadas, 
O PROGRAMA CRIANÇA FELIZ E SUAS CONTRIBUIÇÕES PARA O DESENVOLVIMENTO DA CRIANÇA NA PRIMEIRA INFÂNCIA: APONTAMENTOS SOBRE O CASO DE RIBEIRÃO PRETO/SP

ao longo das visitas domiciliares, com os Supervisores Técnicos do Programa. Nas reuniões periódicas, há momentos de educação continuada permanente da equipe, a partir da discussão de casos sob mediação do Supervisor Técnico e/ ou de outros técnicos convidados, qualificando a todos para o enfrentamento de tais situações se e quando se apresentarem. Com periodicidade semanal, são realizadas as reuniões entre o Supervisores Técnicos do Programa as/os Coordenadoras (es) dos CRAS e Técnicas de Referência do Programa. Nestes encontros são estabelecidas reflexões acerca das demandas observadas e o planejamento estratégico acerca de formas para atendimento e/ou encaminhamento das famílias. Já mensalmente, acontecem as reuniões do Supervisor e Equipe CRAS com a Coordenação e Comitê Gestor Municipal Intersetorial do Programa Criança Feliz (com membros da Assistência Social, Saúde, Educação e Sociedade Civil).

Por meio de observação empírica, durante visitas aos territórios de abrangência do programa, bem como de escuta pessoal junto as famílias atendidas nestas regiões, podemos identificar que o território de abrangência do CRAS 6 apresenta expressiva vulnerabilidade social, bem como escassez de equipamentos públicos (de Saúde, Educação e Assistência Social) no território e a dificuldade das famílias se locomoverem até os equipamentos mais próximos traz, muitas vezes, a sensação de invisibilidade e exclusão social (s.i.c.). Sobre esse assunto, a Política Nacional de Assistência Social (PNAS) de 2004 entende o conceito Vulnerabilidade Social como situação/condição "decorrente da pobreza, privação (ausência de renda, precário ou nulo acesso aos serviços públicos, dentre outros) e, ou, fragilização de vínculos afetivos - relacionais e de pertencimento social (discriminações etárias, étnicas, de gênero ou por deficiências, dentre outras) " (BRASIL, 2004). Em outras palavras, "a fragilização, limitação e/ou ausência do exercício aos direitos político-sociais, constitucionais e humanos de indivíduos, núcleos ou grupos em decorrência de questões políticas e/ou jurídicas" (PADOIN; VIRGOLIN, 2010, p. 1).

\section{A importância do vínculo para o desenvolvimento infantil}

Segundo o Dicionário Michaelis (2016), desenvolver consiste em "[...] passar por um processo de crescimento, e evolução por alterações sucessivas, de um estágio menos perfeito a um mais perfeito ou mais altamente organizado; [...] fazer aumentar ou aumentar a capacidade ou possibilidade de" (WEISZFLOG, 2016). Entendendo neste contexto o "perfeito" como o proativo, o positivo e/ou o prossocial. Ao relacionar o significado do termo "desenvolver" com o assunto do presente trabalho, é possível identificar que o desenvolvimento permeia todo o processo de evolução humana (individual e social). Neste aspecto, o processo de desenvolvimento é também educativo.

Sob tal processo vale lembrar que o Processo de Desenvolvimento Humano, cujo combustível é o Processo Ensino e Aprendizagem, promovido por três processos formativos educativos: Educação Referencial-afetiva (em que 
aprendemos e somos ensinados por nossos pais, nossa família, nossas figuras referenciais afetivas e/ou nossos responsáveis a partir dos valores culturais de ancestralidade na perspectiva consanguínea e/ou de afinidade); Educação Formal-Curricular (em que aprendemos por meio de educadores profissionais e instituições educacionais, a partir de informações, conhecimentos e atividades curriculares e extracurriculares, na perspectiva do conhecimento científico, e que voltam-se a ampliação do nosso repertório pessoal pela transmissão significativa e sistemática); Educação Socioeducativa-Comunitária (não formal, ocorrendo nas interações do vivido-compartilhado pelas relações interpessoais e institucionais socio-comunitárias, não familiares e escolares) (BRASIL, 1996; GAIA, 2017). Posto isso, é possível justificar a importância de analisar os aspectos fundamentais do desenvolvimento infantil, haja vista sua condição de embasar e fortalecer, de modo qualitativo, a ação prática dos Profissionais das Ciências Humanas, num contexto maior de desenvolvimento integral marcado por fases específicas: infância (gestação e nascimento com vida, $1^{\text {a }} \mathrm{e}$ $2^{\mathrm{a}}$ infância), adolescência (pré-adolescência e adolescência plena); juventude; adulto (maturidade) e velhice (última fase até a morte).

O Programa Criança Feliz tem como dimensões do desenvolvimento infantil, a "linguagem, motricidade, dimensão socioafetiva e cognitiva" (BRASIL, 2017, p. 38). Essas dimensões devem ser observadas pelos visitadores durante as visitas domiciliares através das interações lúdicas realizadas entre Visitador Social, cuidador principal e criança (s). Estes aspectos relevantes devem se destacar por meio de indagações realizadas aos cuidadores principais, bem como por meio de observação do caminhar, avanços e dificuldades no desenvolvimento da criança atendida pelo programa. Tudo deve ser registrado no preenchimento dos formulários, instrumentais de registro e controle do programa. Tendo em vista que as crianças atendidas pelo Programa Criança Feliz são contempladas com Visitas Domiciliares sistêmicas para o fortalecimento da relação entre cuidador e criança, e o desenvolvimento infantil, fortalecendo as relações familiares, destacaremos, a seguir a importância da família para o desenvolvimento infantil.

No que se refere à família, temos que ela ainda é o principal contato da criança com o mundo externo (OLIVEIRA; BRAGA; PRADO, 2017) e, especificamente, nos primeiros anos a mãe/cuidador principal é quem media o processo de conhecimento mundo à criança. São eles os responsáveis por traduzir para a criança sensações, emoções e sentimentos, assim como também orienta como viver em sociedade. Por isso, é essencial que o vínculo entre a criança e o seu responsável e seus familiares seja fortalecido (BRASIL, 2017). Para a Psicologia, o vínculo diz respeito ao tipo e a qualidade do relacionamento afetivo que um indivíduo estabelece com outra (s) pessoa (s) (OLIVEIRA, 2000; SILVA; GERMANO, 2015; SPINELLI; FRIGHETTO; SANTOS, 2013). No caso de crianças pequenas (primeira infância, em especial), a relação do vínculo é preconizada pela figura materna ou quem desempenha o papel da maternagem (SILVA; GERMANO, 2015). 
O PROGRAMA CRIANÇA FELIZ E SUAS CONTRIBUIÇÕES PARA O DESENVOLVIMENTO DA CRIANÇA NA PRIMEIRA INFÂNCIA: APONTAMENTOS SOBRE O CASO DE RIBEIRÃO PRETO/SP

A criança nos seus primeiros anos, por estar em fase de desenvolvimento das capacidades motoras e psíquicas básicas para seu funcionamento, tem uma relação de extrema dependência com seu cuidador. Socioculturalmente, esse papel (de cuidador/cuidadora principal) é desempenhado pela figura materna, pois após a gestação, com o nascimento do bebê, a mulher é quem se dispõe a cuidar de seu filho (RABUSKE; OLIVEIRA; ARPINI, 2005; OLIVEIRA, 2000). Assim sendo, quando o cuidado/maternagem ocorre de forma qualificada e qualificadora, sem dúvida alguma, pode-se afirmar que há repercussões e impactos positivos, proativos e prossociais relevantes (OLIVEIRA, 2000) na qualidade e condições das fases seguintes do desenvolvimento humano. Este cuidar integral promove o estreitamento e fortalecimento do vínculo da criança com sua mãe. Processo este que Winnicott (1956) denominou como "preocupação materna primária", pois, nos primeiros anos de vida da criança, a mãe desenvolve uma relação com seu filho em que ela é capaz de decodificar, traduzir e se comunicar com a criança entendendo seus resmungos, choros e desconfortos. Através deste vínculo tão particular, ela apresenta, gradualmente, o mundo que a cerca, transmitindo os valores de sua cultura e suas regras, bem como o reconhecimento das emoções e sentimentos.

O contato sociabilizador da criança com a mãe a partir da dependência nutriz e cuidadora onde se insere, depois para a família ampliada e em seguida para uma sociabilização comunitária e social mais ampla, é fundamental no processo de desenvolvimento infantil em todos os seus aspectos. Sob a perspectiva de Winnicott (Ibid, 1948, p. 237-238), é pertinente entender o papel da mãe de forma continuada, num olhar integral a criança que lhe cabe cuidar, qualificando o desenvolvimento dela e suas capacidades de apropriar-se do tempo e ter o sentimento de um existir interno e pessoal (Ibid.).

Nos bastidores dessa relação entre mãe e filho, encontram-se os familiares e a sociedade na qual a dupla mãe/filho está inserida. É papel das pessoas que estão em volta assegurar que as mães não se sintam inseguras e/ou com medo da sua capacidade de interagir e cuidar de seu filho promovendo o desenvolvimento físico e mental saudável. É preciso que as mães tenham aporte para que "encontrem o seu próprio sentimento, e enquanto o fazem necessitam de apoio - apoio contra os seus medos, suas superstições, suas vizinhas e, obviamente, contra os acidentes físicos e doenças que atualmente podem ser tão facilmente evitados ou curados" (WINNICOTT, 1948, p. 238 - 239).

Quando a mulher, gestante ou mãe, não recebe o apoio necessário para se qualificar e poder cuidar do nascituro que gera (pré-natal) ou do seu filho e auxiliá-los em seu processo de desenvolvimento, a relação do vínculo pode se estabelecer de forma precária e, consequentemente, ocasionar falhas no desenvolvimento da criança. Winnicott (1956) denominou tal suporte falho como sendo um "ambiente não suficientemente bom", porém quando a relação é baseada no vínculo forte e sadio e a mulher recebe o apoio que ela precisa do ambiente, assim, podemos denominar o ambiente como "suficientemente 
bom". Isto propicia a ação e o surgimento de uma "mãe suficientemente boa", favorecendo o desenvolvimento físico e psíquico saudável fazendo com que a crianças e torne capaz de tolerar frustrações e consiga lidar com suas angústias e com o mundo à sua volta. Conforme a criança cresce e se desenvolve adquirindo as habilidades de andar, falar e brincar passa a interagir com o mundo assumindo o protagonismo de sua própria história, e não mais espectador passivo como no começo de sua vida.

Assim sendo, faz-se importante mencionar que, por meio das ações lúdicas, entre elas as brincadeiras, a criança produz cultura e mostra sua condição de lidar com o mundo e com o meio social na qual faz parte (BRASIL, 1998). Esse processo de individualização, independência e habilidade de fantasiar (através do ato de brincar), para Winnicott (1945), indica um relevante progresso para a criança, pois, agora, ela constata que sua mãe não faz parte do seu corpo e mente, e que assim como ele, sua mãe também possui uma individualidade. Este processo diz respeito ao início da separação entre mãe e filho e o fim do período em que a mãe está devota ao seu filho, pois a criança está começando a "dar importância à mãe, à sua sanidade e aos seus estados de espírito" (WINNICOTT, 1945, p. 222).

Com a inserção da criança no convívio escolar, podemos perceber a capacidade da criança estar só, podendo experimentar a convivência mais autônoma consigo mesmo e com o outro (sociabilização). Segundo Winnicott (1958) este é um dos sinais mais importantes do amadurecimento e desenvolvimento emocional de uma pessoa. A habilidade de estar só, de acordo com Winnicott (Ibid.), se dá através:

[...] da experiência precoce de estar só na presença de alguém. Estar só na presença de alguém pode ocorrer num estágio bem precoce, quando a imaturidade do ego é naturalmente compensada pelo apoio do ego da mãe. À medida que o tempo passa o indivíduo introjeta o ego auxiliar da mãe e dessa maneira se torna capaz de ficar só sem apoio frequente da mãe ou de um símbolo da mãe (Ibid., p. 34).

Mediante ao exposto, é necessário compreender que tal acontecimento expõe que a criança teve oportunidades de se desenvolver em um ambiente suficientemente bom que a auxiliou a adquirir progressivamente a capacidade de lidar com o mundo, identificar-se com a sociedade na qual vive, percebendo que ela (a criança) tem voz para expressar seus sonhos e desejos, e percebendo que a sociedade a qual faz parte é como um exemplo de seu mundo interno. Desta forma a criança se desenvolve, protagonizando sob mediação educadora, sua autonomia e independência pessoal, tornando-se capaz de viver em sociedade de modo satisfatório.

Desse modo, a observação do desenvolvimento da criança desde seu nascimento é um ponto de partida para compreender o desenvolvimento hu- 
O PROGRAMA CRIANÇA FELIZ E SUAS CONTRIBUIÇÕES PARA O DESENVOLVIMENTO DA CRIANÇA NA PRIMEIRA INFÂNCIA: APONTAMENTOS SOBRE O CASO DE RIBEIRÃO PRETO/SP

mano (WINNICOTT, 1990; SILVA, 2016), que ocorre, dentre outros fatores, sob os aspectos psíquicos, físicos, afetivos (WINNICOTT, 2011) e também sociais. Fundamentado nesses dados é possível salientar que a promoção do desenvolvimento humano está entre os objetivos do PCF e sua promoção ocorre por meio de mediação/intervenção, escuta ativa e qualificada durante as visitas e acompanhamentos (semanais, quinzenais e/ou mensais) dos beneficiários do programa e seus familiares (BRASIL, 2017) conforme estabelecido pelos documentos oficiais do programa.

\section{Considerações finais}

Diante do exposto, pode-se apresentar a organização do Programa Criança Feliz e sua metodologia de atuação, por meio de análise de seus instrumentais e aspectos jurídicos, também por meio de sua operacionalidade no Município de Ribeirão Preto - SP. Válido lembrar que o programa em pauta se encontra no nicho de programas ofertados pela Assistência Social no Brasil, através do Ministério de Desenvolvimento Social (MDS). Em decorrência disso, o PCF tem como público as pessoas em vulnerabilidade social, crianças de zero a três anos de idade e gestantes beneficiarias do Programa Bolsa Família e crianças em primeira infância beneficiarias do Benefício de Prestação Continuada (BPC).

É pertinente ressaltar que o programa é, de certo modo, "novo" para a Assistência Social, aspecto esse que não advém somente por sua constituição recente, mas também pelo seu recorte e metodologia de visitas domiciliares sistêmicas (com periodicidade definida pelas diretrizes do programa). Entre os objetivos do Programa Criança Feliz está o apoio às gestantes no que se refere a sua gestação e a promoção do "desenvolvimento humano a partir do apoio e do acompanhamento do desenvolvimento infantil integral na primeira infância" (BRASIL, 2017, p. 9), tendo o fortalecimento de vínculo como ferramenta e objetivo. Evidencia-se que o Programa Criança Feliz não tem como objetivo a sobreposição ou substituição do PAIF, mas o trabalho em conjunto entre organizações no que se refere ao levantamento das demandas observadas durante às visitas domiciliares.

O ser humano está em constante desenvolvimento, no entanto, a atenção e o cuidado com as crianças, principalmente nos primeiros anos de idade, é fundamental, pois é nesse período que a estruturação física e mental do indivíduo começa a se desenvolver. Com isso, é valido ressaltar que diversos fatores afetam o desenvolvimento da criança, como a alimentação, o ambiente e as relações humanas (familiares e sociais). Contudo, a atenção e o cuidado no desenvolvimento da criança inicia-se anteriormente ao nascimento, haja vista a prudência e preparação da gestante para o nascimento do bebê. Neste aspecto, as intervenções realizadas pelas Visitadoras Sociais durante as visitas domiciliares do PCF servem como eixo mediador buscando o desenvolvimento humano, especificamente da criança em vulnerabilidade social (BRASIL, 2017). 
O Programa Criança Feliz é um programa novo, inclusive de concepção, e traz uma metodologia e um recorte inovadores à Assistência Social (as visitas domiciliares programadas e sistêmicas às gestantes e crianças em primeira infância). Embora os resultados obtidos durante o desenvolvimento da criança e o efetivo alcance dos objetivos estabelecidos pelos documentos oficiais de concepção do PCF, em decorrência do curto prazo de vigência do programa, acredita-se que quando os fatores propostos pelo Guia para Visita domiciliar com embasamento no método CDC ocorrem, desde que em parceria com o CRAS e de forma intersetorial e em rede, poderão proporcionar efeitos positivos. Isso resulta em melhor acesso aos serviços, projetos, programas e benefícios socioassistenciais e intersetoriais, o que auxilia no desenvolvimento humano de forma integral que certamente irá refletir no cotidiano dos indivíduos beneficiários do Programa.

Pode-se concluir que o Programa Primeira Infância no SUAS, Programa Criança Feliz- (PCF), tem entre outros duas conquistas muito relevantes: primeiro, qualificar, melhorar e incentivar de forma integrada e complementar o PAIF junto aos CRAS/SUAS, melhorando a resolutividade do atendimento para as famílias e indivíduos que acompanha; e, segundo, levar a ação socioassistencial a vencer determinadas barreiras e desafios, na perspectiva de atuar com mais amplitude, tranquilidade e rotina cotidiana no viés de intersetorialidade e interdisciplinaridade, passando a discutir o cofinanciamento, não só interfederativo (Federal + Estadual + Municipal), mas também Intersetorial (políticas diversas). Este último item amplia o olhar para o público-alvo de forma mais integral e menos compartimentada, modulada, parcial, como deve ser e manda a doutrina da Proteção Integral, além do avanço da ação multidisciplinar (juntos, mas segregados), no mínimo para uma a ação interdisciplinar, juntos, segregados, mas em busca de um olhar comum, integrado, único. Isto pode abrir portas futuras para alcance de um olhar transdisciplinar, derrubando barreiras e resistências e garantindo uma ação omnilateral dos agentes e um olhar integral ao indivíduo sujeito com o qual atuarem.

\section{Referências}

ALAYÓN, Norberto. Assistência e Assistencialismo: controle dos pobres ou erradicação da pobreza?. 2. ed. São Paulo? Cortez, 1995

BRASIL. CNAS. Resolução n. 09, de 15 de abril de 2014. Brasília: MDS, 2014.

BRASIL. CNAS. Resolução n. 17, de 20 de junho de 2011. Brasília: MDS, 2011.

BRASIL. Constituição da República Federativa do Brasil. Brasília, DF: Senado Federal: Centro Gráfico, 1988. 292 p.

BRASIL. Decreto n. 8.869, de 05 de outubro de 2016. Diário Oficial da União, Poder Executivo, Brasília, DF, 06 out. 2016a.

BRASIL. Decreto n. 13.257, de 08 de março de 2016. Diário Oficial da União, Poder Executivo, Brasília, DF, 08 out. 2016b.

BRASIL. Lei de Diretrizes e Bases da Educação Nacional - LDBEN. Lei n. 9.394, de 20 de dezembro de 1996. 
O PROGRAMA CRIANÇA FELIZ E SUAS CONTRIBUIÇÕES PARA O DESENVOLVIMENTO DA CRIANÇA NA PRIMEIRA INFÂNCIA: APONTAMENTOS SOBRE O CASO DE RIBEIRÃO PRETO/SP

BRASIL. Lei $\mathbf{n . ~ 8 . 6 6 2 , ~ d e ~} 7$ de junho de 1993. Dispõe sobre a profissão de assistente social e dá outras providências. Diário Oficial da União, Poder Legislativo, Brasília: DF, 8 jun. 1993b.

BRASIL. Lei $\mathbf{n} . \mathbf{1 1 . 7 8 8}$, de $\mathbf{2 5}$ de setembro de 2008. Dispõe sobre o estágio de estudantes e dá outras providências. Diário Oficial da União, Brasília, 26 set. 2008.

BRASIL. Lei $\mathbf{n}^{\circ}$ 13.019, de 31 de julho de 2014. Estabelece o regime jurídico das parcerias voluntárias, envolvendo ou não transferências de recursos financeiros, entre a administração pública e as organizações da sociedade civil, em regime de mútua cooperação, para a consecução de finalidades de interesse público; define diretrizes para a política de fomento e de colaboração com organizações da sociedade civil; institui o termo de colaboração e o termo de fomento e altera as Leis nos 8.429, de 2 de junho de 1992, e 9.790, de 23 de março de 1999. Disponível em: <http://www.planalto.gov.br/ccivil_03/_Ato2011-2014/2014/Lei/ L13019.htm> Acesso em: 20 jan. 2019.

BRASIL. Lei Orgânica da Assistência Social - L.O.A.S., Lei n. 8.742. Brasília: DF, de 7 set. $1993 a$.

BRASIL. Ministério de Desenvolvimento Social. Criança Feliz: guia para visita domiciliar Brasília: Secretaria Nacional de Promoção do Desenvolvimento Humano, 2017. 112 p.

BRASIL. Portaria n 2.496, de 17 de setembro de 2018. Diário Oficial da União, Brasília, 18 set. 2018.

BRASIL. Resolução n. 6, de 19 de fevereiro de 2019. Conselho Nacional de Assistência Social - CNAS. Diário Oficial da União, Brasília, 20 fev. 2019.

BRASIL. Ministério da Educação e do Desporto. Secretaria de Educação Fundamental. Referencial Curricular Nacional para a Educação Infantil. Ministério da Educação e do Desporto, Secretaria de Educação Fundamental. v. 3. Brasília: MECISEF, 1998.

BRASIL. Ministério do Desenvolvimento Social e Combate a Fome. Política Nacional de Assistência Social (PNAS). Brasília, DF, 2004.

GAIA, R. S. P.. Educação Especial no Brasil: análises e reflexões. Revista Transversal, Assis, n. 10, p. 69-80, 2017. Disponível em: < http://uniesp.edu.br/sites/_biblioteca/revistas/20170719100610.pdf>. Acesso em: 8 jan. 2019.

GAIA, R. S. P.. Reflexões acerca da inserção do Pedagogo no Centro de Referência da Assistência Social (CRAS). Revista Pedagogia UFMT, Cuiabá, v. 3, n. 2, p. 213-226, 2016. Disponível em: < https://docs.wixstatic. com/ugd/663f6b_9b30c74aba624ddd8cd28b0f53e577ea.pdf>. Acesso em: 14 fev. 2019.

OLIVEIRA, I. L. S.; BRAGA, A. P.; PRADO, C. M. N.. Participação da família no desenvolvimento da aprendizagem da criança. Estação Científica (UNIFAP), Macapá, v. 7, n. 2, p. 33-44, 2017.

OLIVEIRA, R. A.. Do vínculo às relações sociais: Aspectos psicodinâmicos. Análise Psicológica, Lisboa, v. 18, n. 2, p. 157-170, 2000.

PADOIN, I. G.; VIRGOLIN, I. W. C.. A vulnerabilidade social como uma dificuldade a participação política. In: XV Seminário Interinstitucional de Ensino, Pesquisa e extensão. Cruz-Alta: UNICRUZ, 2010. Disponível em:<http://www.unicruz.edu.br/15_seminario/seminario_2010/CCSA/A\%20VULNERABILIDADE\%20 SOCIAL\%20COMO\%20UMA\%20DIFICULDADE\%20A\%20PARTICIPA\%C3\%87\%C3\%830\%20 POL\%C3\%8DTICA.pdf>.Acesso em 12 mar. 2019.

PMRP. Prefeitura Municipal de Ribeirão Preto. Centro de Referência da Assistência Social - CRAS. Ribeirão Preto: Secretaria Municipal de Assistência Social - SEMAS. Disponível em: <https://www.ribeiraopreto.sp.gov.br/ scidadania/atendimento/i27cras.php.>. Acesso em 11 mar. 2019.

RIBEIRÃO PRETO. Edital de Chamamento Público, n. 5/2017 - SEMAS. Secretaria Municipal de Assistência Social. Prefeitura Municipal de Ribeirão Preto. Ribeirão Preto: SEMAS, 2017.

RIO GRANDE DO SUL. Lei Estadual n. 12.544. Institui o Programa Primeira Infância Melhor e dá outras Providências. Porto Alegre: Governo do Estado do Rio Grande do Sul, 03 de julho de 2006.

RIO GRANDE DO SUL. Secretaria Estadual da Saúde. Portaria n. 15/2003. Porto Alegre, 2003.

SILVA, S. G.. Do feto ao bebê: Winnicott e as primeiras relações materno-infantis. Psicologia Clínica, Rio de Janeiro, v. 28, n. 2, p. 29-54, 2016. 
SILVA, M. R. C.; GERMANO, Z.. Perspectiva psicanalítica do vínculo afetivo: o cuidador na relação com a criança em situação de acolhimento. Psicologia Ensino \& Formação, São Paulo, v. 6, n. 2, p. 37-53, 2015.

Sistema de Informação e Gestão da Assistência Social de Pernambuco. Serviços Socioassistenciais. Pernambuco: SIGAS. Disponível em: <https://www.sigas.pe.gov.br/pagina/servios-socioassistenciais>. Acesso em: 23 nov. 2018

SPINELLI, A. A.; FRIGHETTO, A. M.; SANTOS, J. C.. Como a Família Influencia no Bom Desenvolvimento na Vida das Crianças. Nativa - Revista de Ciências Sociais do Norte de Mato Grosso, Guaratã do Norte, v. 1, n. 2, p. 1-12, 2013.

WEISZFLOG, W.. Desenvolvimento. In: WEISZFLOG, Walter. Dicionário Michaelis: Melhoramentos, 2016. Disponível em:<http://michaelis.uol.com.br/busca?r=0\&f=0\&t=0\&palavra=desenvolvimento>. Acesso em: 25 nov. 2018.

WINNICOTT, D. W.. (1958). A capacidade para estar só. In: O ambiente e os processos de maturação. Estudos sobre a teoria do desenvolvimento emocional. Porto Alegre: Artmed, 2007.

WINNICOTT, D. W.. A família e o desenvolvimento individual. 4. ed. São Paulo: Martins Fontes, 2011.

WINNICOTT, D. W.. (1956). A preocupação materna primária. In: Da pediatria à psicanálise. Obras escolhidas. Rio de Janeiro: Imago, 2000.

WINNICOTT, D. W.. (1945). Desenvolvimento emocional primitivo. In: Da pediatria à psicanálise. Obras escolhidas. Rio de Janeiro: Imago, 2000.

WINNICOTT, D. W.. (1948). Pediatria e Psiquiatria. In: Da pediatria à psicanálise. Obras escolhidas. Rio de Janeiro: Imago, 2000

WINNICOTT, D. W.. Natureza humana. Rio de Janeiro: Imago, 1990. 